ISMC 2021

$16^{\text {th }}$ International Strategic Management Conference

\title{
OPPORTUNITIES FOR SUPPLY CHAIN MANAGEMENT IN AGRIBUSINESS
}

\author{
Ayaz Tagiyev (a)* \\ *Corresponding author
}

(a) Azerbaijan State University of Economics (UNEC) Chair of Business Administration, Inshaatchilar Avenue, Baku, Azerbaijan, mba_az@mail.ru

\begin{abstract}
The purpose of the study is to identify the main features of supply chain management in agribusiness and to explore the opportunities that it creates for entrepreneurs. The work uses the methods of logistics, management, reengineering of business processes, mathematical methods of optimization. To solve the set tasks, the author also used general scientific methods (analysis, synthesis, systemic and complex analysis), special methods (comparisons, sample observation, statistical methods), economic and sociological research (questionnaire survey, secondary analysis of economic research), etc. The article shows that one of the largest areas of the supply chain management (SCM) practice in the world is the agricultural sector. The newly proposed "supply chain" is a managed process. SCM differs significantly from traditional management. If we take into account that there are opportunities to expand inter-firm relations (horizontal integration) operating in each link of the supply chain, then it becomes clear that the synergistic effect created by SCM is strong. On the other hand, the integration of two or more links in the supply chain (vertical integration) can create an additional synergistic effect.
\end{abstract}

2357-1330 @ 2021 Published by European Publisher.

Keywords: Horizontal integration, supply chain, supply chain management, traditional management, vertical integration 


\section{Introduction}

Liberalization of the economy as the business environment expands, the state shifts the burden of economic activity to private business as much as possible. Private businesses are trying to be more independent. However, practice shows that in order to stay in the market and build a more profitable business, there is a need to reduce transaction costs and take advantage of the scale effect. A clear example of this is more obvious in the agricultural sector. Thus, the large number of individual landowners who emerged after the agrarian reforms were very inclined to cultivate or raise livestock on their land. but it soon became clear that it was very difficult to plant, collect, transport, and sell any crop within a family. It is not possible to study agro-technical requirements to increase productivity or to provide veterinary services to an entrepreneur engaged in animal husbandry. Decreased productivity was inevitable due to the lack of division of labor. Unfortunately, despite the current situation in the agricultural sector of Azerbaijan, we do not see any examples of large-scale supply chain (SC). However, one of the largest areas of the supply chain management (SCM) practice in the world is the agricultural sector.

Modern trends in the development of agribusiness are experiencing, on the one hand, the influence of the internal desire of enterprises, producers of agricultural products for autonomy and independence, and on the other hand, the desire for maximum conjugation of logistics operations by all participants in the supply chains. These requirements predetermine the need to search for forms and methods of integrating interaction between the links of the supply chain in the framework of coordinating the efforts of enterprises and centralizing the material and information support of the process of selling agricultural products.

\section{Literature Review}

Over the last 30 years, there has been a great deal of research in the economic literature on the supply chain and its management. The supply chain covers all processes from production to consumption of any goods and services. This reflects the flow of materials and information used in the production, storage, transportation and sale of goods and services, as well as money. Chopra and Meindl (2001) as noted in their research, the supply chain also includes marketing activities, distribution, financing, etc. related to the creation and launch of a new product. In this case, each link in the supply chain may belong to a firm (or firms) operating in that loop. A company can operate in several circles.

In fact, the chain, which covers the processes from production to consumer, is not new. The four main stages of the production process - production, distribution, exchange and consumption - were known long before the concept of "supply chain" came to the literature. However, the "rings" that make up such a traditional "chain" were not studied as a cycle in relation to other rings, and the activity of one ring did not depend on the other rings. At the heart of the supply chain is the ability of all the links in such a chain to operate in unison and to be managed as a single process. That is, in the traditional sense, it was possible to manage production cycles separately, but the ability to manage all cycles together was limited. The newly proposed "supply chain" is a managed process. This process introduces the concept of "supply chain management". 
As we noted, "the supply chain management" is a new concept and was first introduced in 1982 by Oliver and Weber in the literature on logistics in the approach to inventory management related to the supply of raw materials (Christopher, 1992). In the following years, the problem of reducing costs during the movement of goods and services from the production process to the consumer expanded the research on SCM. The main focus of the research was to reduce costs and meet consumer demand by expanding cooperation between the links in the supply chain. SCM assumes that a firm in any link in this chain seeks to optimize cooperation rather than optimize its operations to generate higher returns. Cooper and Ellram (1993). According to the study conducted by, the differences between SCM and traditional management can be classified as in Table 01:

Table 1. The differences between SCM and traditional management

\begin{tabular}{|c|c|c|}
\hline Element & Traditional management & Supply chain management \\
\hline $\begin{array}{l}\text { Approach to inventory } \\
\text { management }\end{array}$ & Independent efforts & Joint efforts to reduce inventory \\
\hline Approach to total costs & Minimize the firm's costs & $\begin{array}{l}\text { Achieving economic efficiency } \\
\text { throughout the relationship }\end{array}$ \\
\hline Duration of activity & For a short period & For a long period \\
\hline $\begin{array}{l}\text { volume of information } \\
\text { exchange and monitoring }\end{array}$ & Limited to current transaction & $\begin{array}{l}\text { As much as required for planning and } \\
\text { monitoring purposes }\end{array}$ \\
\hline $\begin{array}{l}\text { The sum of the agreed levels } \\
\text { in the relationship }\end{array}$ & $\begin{array}{l}\text { Single contact for transaction } \\
\text { between each pair of contacts }\end{array}$ & $\begin{array}{c}\text { multilateral contacts depending on the } \\
\text { level of connections and levels in } \\
\text { firms }\end{array}$ \\
\hline Joint planning & According to the transaction & Resistant \\
\hline $\begin{array}{l}\text { Correspondence of corporate } \\
\text { philosophy }\end{array}$ & It does not matter & $\begin{array}{c}\text { there is compatibility for at least basic } \\
\text { relationships }\end{array}$ \\
\hline $\begin{array}{l}\text { breadth of activities of the } \\
\text { main supplier }\end{array}$ & $\begin{array}{c}\text { It is great to be competitive and to } \\
\text { reduce risk }\end{array}$ & It gets smaller to improve coordination \\
\hline relationship management & Not required & Required to focus on coordination \\
\hline $\begin{array}{l}\text { The amount of distribution of } \\
\text { risks and rewards }\end{array}$ & Everyone has their own risks & $\begin{array}{c}\text { Distribution of risks and rewards over } \\
\text { a long period of time }\end{array}$ \\
\hline $\begin{array}{l}\text { speed of flow of operations, } \\
\text { information and inventory }\end{array}$ & $\begin{array}{c}\text { "Warehouse" is inclined (storage, } \\
\text { security and warehousing). It } \\
\text { usually does not flow and is } \\
\text { localized for double contact }\end{array}$ & $\begin{array}{l}\text { "Turnover rate" is available. } \\
\text { Coordinating flows are also available }\end{array}$ \\
\hline
\end{tabular}

Table 01 shows that SCM differs significantly from traditional management. If we take into account that there are opportunities to expand inter-firm relations (horizontal integration) operating in each link of the supply chain, then it becomes clear that the synergistic effect created by SCM is strong. On the other hand, the integration of two or more links in the supply chain (vertical integration) can create an additional synergistic effect.

Fisher (1997) defined the right supply chain by product. In his work, techniques such as Electronic Data Interchange (EDI), Efficient Customer Response, Point of Sales, flexible production techniques, lean production, agile production, mass production, Accurate Response in the supply chain. It has been emphasized that even if implemented, the performance of the supply chain will not be at the desired level. In order to talk about an effective supply chain, it is necessary to consider the demand structure of the products supplied by that company. In this research, products are divided into functional and innovative 
according to the demand structure. Functional products need an efficient process, while innovative products need a responsive process. Thus, a firm can have an efficient supply chain by changing its product or supply chain.

Mabert and Venkataramanan (1998) also explained the differences between Supply Chain management and Logistics and introduced supply chain design elements in general. In addition, their studies are grouped as follows: 1) In addition to sharing information between vertically connected companies, cooperation between companies that are not vertically connected but have commercial business relations, 2) Besides the material flow in the supply chain, the market progressing parallel to this material flow, designing the supply chain, including finance and human resources management; 3) Implementation of supply chain management, which also takes into account the new product development and quality process; 4) Consideration of issues such as material handling, packaging, information technologies and production during the design of the supply chain, 5) Considering the supply chain not only for those at the production level, but also for the service sector such as health and financial services.

Viswanathan and Piplani (2001) have shown that the performance of the supply chain improves with the use of a joint renewal program or joint periods in Supply Chain Management. For this, the structure in which there is a single seller and many retailers has been examined. In this research, they determined order renewal periods for vendor-retailers and ensured that orders were placed during these periods. They also offered price reductions to retailers so that retailers would accept this. In this approach, it is emphasized that order cost must be above a certain threshold value for an improvement in the total supply chain cost.

In his study, Kim (2000) emphasized that the main reason for the companies in the supply chain to establish relations with each other is the cooperation between these elements. It was emphasized that in order to maintain such a relationship, not only the profitability of the producers but also the profitability of the suppliers should be taken into consideration. In the study, they emphasized that although cooperation reduces the costs of the manufacturer, it is unacceptable for retailers unless there is a certain increase in end-user demands. Therefore, the article shows whether such cooperation is acceptable for both the manufacturer and the retailer.

Ellinger et al. (1999) emphasized that communication between vendors and retailers forms the basis of supply chain philosophy. In particular, fully meeting the detailed requests of end users and customer loyalty have made cooperation in the supply chain even more important. Highly satisfied customers are more loyal than less satisfied customers. In the research, the supply chain was examined in terms of customer satisfaction and customer loyalty.

Yao and Carlson (1999) reported in their study that in batch production of most distribution systems, the delay of data such as stock quantities, stock locations and movements can cause unbearable costs for the business. The methods used to prevent this are listed as barcoding scanning and radio waves. In their research, they examined the effect of radio waves on the supply chain. They have shown that with this method, most companies increase their productivity and customer satisfaction rate and reduce distribution costs.

Lim and Palvia (2001) focused on the hypothesis that EDI increases the level of customer service in their study. In addition to this hypothesis, they revealed that many hypotheses examined were 
supported as a result of their examination in the automobile and pharmaceutical industry. Thanks to EDI, it has been observed that there is an improvement in order time, product availability, distribution flexibility, distribution information and defects observed in distribution.

\section{Purpose of the Study and the Research Methods}

The purpose of the study is to identify the main features of supply chain management in agribusiness and to explore the opportunities that it creates for entrepreneurs. The theoretical and methodological basis of the work was made up of monographs, scientific articles, reports and speeches at international scientific and practical conferences of domestic and foreign scientists on commerce and logistics, strategic management, general economic theory.

The work uses the methods of logistics, management, reengineering of business processes, mathematical methods of optimization. To solve the set tasks, the author also used general scientific methods (analysis, synthesis, systemic and complex analysis), special methods (comparisons, sample observation, statistical methods), economic and sociological research (questionnaire survey, secondary analysis of economic research), etc.

\section{Findings}

\subsection{The essence of the supply chain management}

The economic literature distinguishes three main decisions in the SCM process. For example, Lambert and Cooper (2000) these decisions are classified as follows: 1) members of the supply chain should know who else is included in the network and with whom they should be contacted; 2) in what process it is necessary to communicate with these members of the supply chain; 3) what level of integration or management should be applied to the communication necessary to carry out this process. The decision-making process is also associated with various steps. According to a study by Lambert and Cooper (2000), the supply chain 1) begins with the selection of its object; 2) SCM is established. These include a) business processes of SC, b) components of SC management and c) network structure of SC. The main decisions necessary for SCM are made at this stage. The last 3) stage of SC is related to its activity (Figure 01).

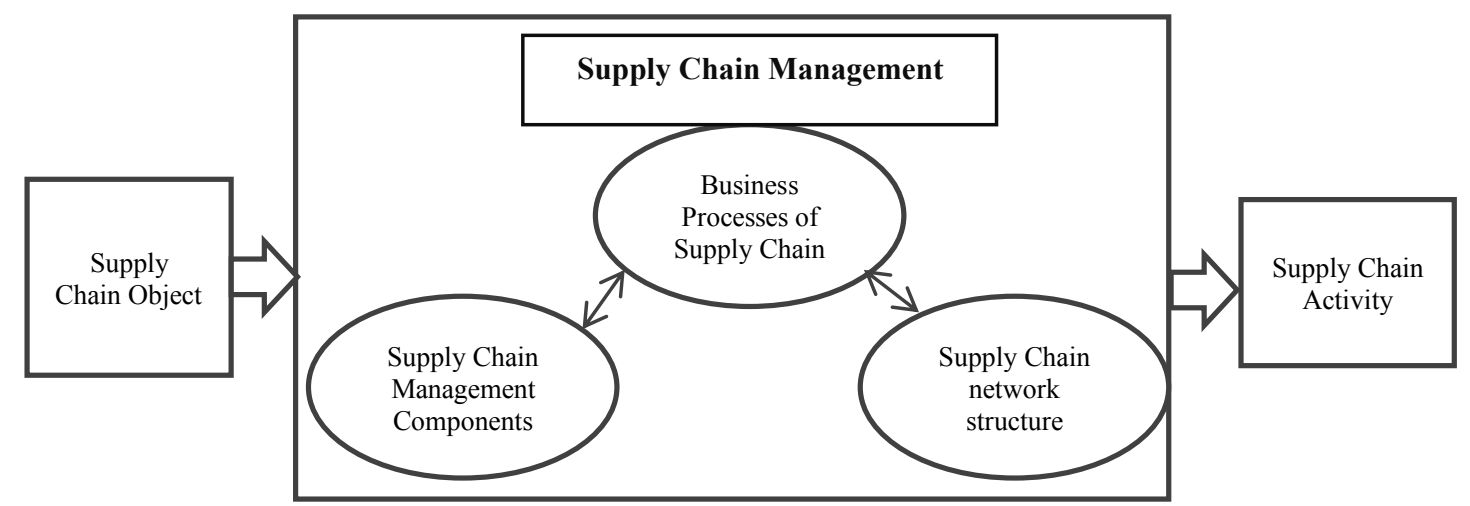

Figure 1. Stages of SCM 
The supply chain is much more than the functioning of the planned economic system that existed in the former USSR looks like, but is essentially completely different. Thus, in the planned Soviet economy, all processes, from the production of any goods or services to their delivery to the consumer, were carried out in a coherent manner. For example, the scheme of delivery of grape wine to consumers in Russia was as follows: grapes grown in many orchards belonging to different state or collective farms in Azerbaijan were collected (ring 1 of the supply chain) and delivered to the grape supply plant (ring 2). The plant also imported any product from other suppliers, such as alcohol. After the necessary processes for the production of wine were carried out and the wine was ready, it was sent to another factory for packaging (ring 3). Grape wine packaged for sale was then shipped to various cities, including Russia. It was sent to wholesale outlets in Ukraine and other countries (4th ring). From such wholesale outlets, they were sent to retail stores (the last ring).

Thus, the grapes produced in various collective and state farms of Azerbaijan were delivered as wine to consumers living in other countries. Although this simple scheme we describe is similar in form to SCM, it is fundamentally different. The main difference is that the links in the supply chain were not controlled by them and the order was not formed by mutual agreement. For example, no agreement was reached with the receiving plant on the price of grapes. Or there was no price agreement between the winery and the winery. The prices of finished products sent to other countries for sale were also determined by the relevant government agencies. One of the main differences of such a chain from the "supply chain" in the modern economic literature is the lack of information flow. Thus, although there is an uncoordinated financial flow along with the flow of goods and services, the flow of information does not occur. SCM provides information flow as well as physical and financial flows (Dubey et al., 2020). Enterprises included in the SC are informed about the volume and demand for their products. information flow does not occur. SCM provides information flow as well as physical and financial flows. Enterprises included in the SC are informed about the volume and demand for their products. information flow does not occur. SCM provides information flow as well as physical and financial flows. Enterprises included in the SC are informed about the volume and demand for their products.

The supply chain we are considering management is formed on the basis of joint decisions of individual independent firms included in such SC. However, the existence of dominant links in the process of its management is not excluded. On the contrary, such dominant links or a dominant member within a ring can play an important role in ensuring the effectiveness of cooperation and coordination in the SCM process of other members (Budiarto et al., 2017). For example, the process of selecting the object of the SC and the inclusion of other faces in this process is not so easy. For example, Why is it not possible to create the SC necessary for Azerbaijani wine to enter the markets of other countries on the basis of the above-mentioned scheme? Why can't grape growers or individual entrepreneurs hand over their products to independent wineries at agreed prices? That is, why can't the 1st ring of SC agree with the 2 nd ring of SC, ie with the wineries in the field of price? Unfortunately, even though wineries agree on the packaging of the wines they produce (ring 3), the ability of such packaging plants to develop SC with ring 4, which sells wholesale in foreign countries, is a serious problem. Ensuring that this link in the supply chain is integrated into the SCM network is one of a number of indicators, in some cases. 
The supply chain is both as a whole organization can be managed as a system of a large number of coordinated elements. In this case, it is necessary to agree on the goals and objectives of the SC among the members. Unlike the Soviet supply system we have considered above, it is important to reach agreements between the members of the SC. Otherwise, any member of the SC or most of the members of the circle may delay the activity of the SC (Hasanli et al., 2019). For example, if a SC for the production of school uniforms is established and the first link in this chain is the entrepreneurs who produce cotton, then the companies that supply raw cotton must take into account their interests when ordering them. Otherwise, the supply of cotton will weaken next year, and the 1st ring of SC will have a serious impact on gross income and activity.

\subsection{Supply chain in agribusiness}

Chandrasekaran and Raghuram (2014) by comparing SCM in agribusiness with SCM in other sectors, they come to the conclusion that agribusiness participants are 1) resource owners; 2) suppliers of funds necessary for production; 3) producers; 4) market for direct consumption; 5) processors; 6) open market; 7) retail sales; 8) consumers; 9) financial agents and those influencing physical flow. They believe that resource owners have an important role to play in SC. They may not be directly involved in production, but since their resources, such as land, are used in the production process, such participants should also be included in the SC (Hitt et al., 2016). In the agricultural sector, the production process is not possible or productive without seeds, fertilizers, machinery, etc. Therefore, it is important that equipment with such "input goods" or factors is also included in the SC. Chandrasekaran and Raghuram (2014) also include labor in the list of such "input factors". The efficiency of the "input factors" market has a significant impact on the efficiency of the SC. Thus, the quality of seeds or fertilizers, as well as the provision of machinery by the manufacturer has a direct impact on productivity.

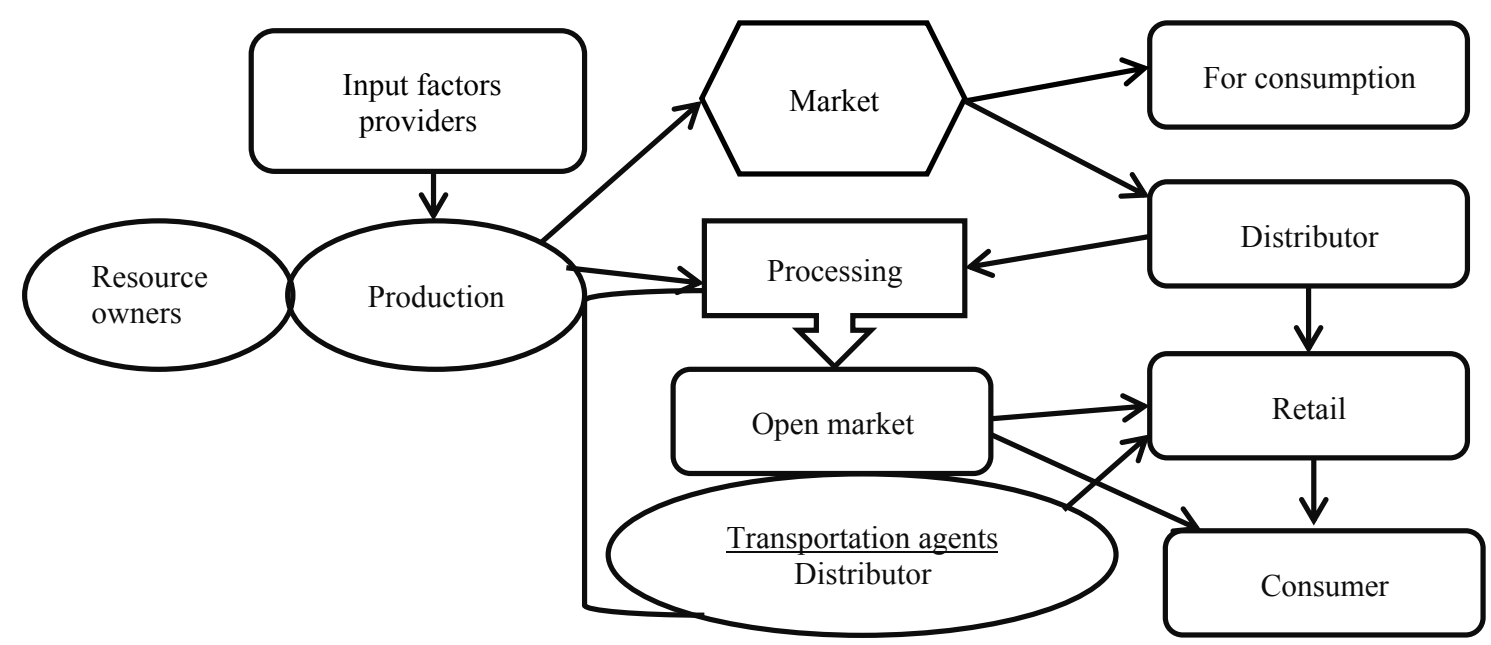

Figure 2. Simplified scheme of agribusiness SCM

In agribusiness, according to the scheme SCM given by Chandrasekaran and Raghuram (2014) (Figure 2), a certain part of the product produced in the agricultural sector, unlike other sectors, enters the market both through the processing stage and directly. The economic literature notes the dependence of 
SC on two criteria in agribusiness (Harshit et al., 2021; Matsubara, 2011; Vitorino Filho \& Moori, 2020). First, how do goods and services "move" from producer to consumer? Depending on the nature of this action, the effectiveness of the SCM is assessed. Second, how does SCM meet the needs of consumers? These criteria are determined by various factors.

SC-One or more firms may operate on each ring. For example, in the agricultural sector, a cotton supply point usually receives produce from a large number of farmers. The cotton processing plant can also receive cotton from a large number of points. Cotton mills can also accept such yarns from factories that produce a large number of cotton yarns. There may also be several wholesale outlets for finished fabric products. The presence of a large number of firms in each circle of the SC raises the issue of integration of such firms (Miethlich et al., 2020). Thus, it is possible for firms operating on the same ring to integrate on a single firm scale, or for multiple rings to integrate within a single company. In the first case there is a horizontal integration of firms, and in the second case there is a vertical integration. Both types of integration reduce costs in the SC, including transaction costs.

\subsection{New Technologies in Agribusiness SCM}

A number of new technologies are changing the way SCM works in agribusiness. IT can provide information on a wide range of product attributes and is an effective and important way to coordinate activities in the supply chain (Hannus et al., 2003). Electronic data interchange, product identification and registration systems such as EDI-pigs and EDI-flowers in the Netherlands, and quality assurance systems to guarantee product quality and increase competition by doing so are examples of IT methodologies.

It is recommended that the characteristics of agricultural products be considered in making decisions about IT-based coordination of the supply chain (Fisher, 1997). The nature of the product being sold is the main characteristic of interest here, and more specifically, understanding whether the product is "functional" or "innovative". Functional products are those with predictable demand. Innovative products are differentiated, have many varieties and often show short life cycles.

According to Fisher (1997), the main purpose of SCM for a functional product should be to reduce the costs of physical functions along the chain. Typical IT examples for physical functions include automating order processes and payment mechanism, scheduling storage, distribution and control system for quality assurance in production (Salin, 1998). SCM of innovative products should focus less on costs and more on providing the attributes consumers desire. Consumer demand is the main factor to be analyzed and the selection of suppliers should be based on speed and flexibility. The problem with innovative products is that companies promoting such products do not know their consumption rates in advance, so the ideal SCM is sensitive. The essential tools for this responsive execution are SC production and systems that link orders to sales to limit stockouts or overstocking. On the other hand, the IT systems used are browser data collection and customer loyalty cards that allow food retailers to predict consumer desires.

Many IT systems have been implemented in agribusiness SCM situations to offer solutions to food-specific issues. For example, food safety issues are very important in the agricultural chain. Rapid identification and response to food safety problems requires the ability to trace even small product quantities to their origin, from retailer to producer or farm. IT systems covering barcoded products 
produce the necessary solution in all stages of processing departments. Another food-specific issue that can be managed by implementing IT systems in SCM is supply variation due to biological cycle and weather conditions. This change causes food input costs to change because the cost of raw materials is not easily controllable and perhaps unpredictable. The unpredictability of this supply makes it necessary for SCM to better understand product markets using various sources of information. Finally, seasonality in agricultural production (especially for grain crops) may affect SCM approaches. However, no amount of IT investment can eliminate the need for long-term storage of products (Salin, 1998).

E-commerce is the latest IT methodology in agriculture. It has become widespread with the development of the Internet. Common agribusiness transactions such as buying, selling, trading, distributing and contracting appear to be natural targets for conversion to e-commerce. The main theoretical benefits of e-commerce in agricultural business; speeding up transactions related to information flow, market transparency and price determination, facilitating industry coordination, reducing or eliminating transaction costs (Leroux et al., 2001). Internet-based e-commerce is a very new phenomenon. There are many e-commerce business models available, such as auctions, exchanges, and catalogues. Sachs (2000) discussed the common barriers cited by businesses for the adoption of internetbased e-commerce. These are uncertain return on investments, lack of stakeholder support, and complex technology.

\section{Conclusion}

Today, it is necessary to understand the importance and benefits of the supply chain management system, which is accepted as one of the e-business systems that is of vital importance for the company, and which is well understood to be implemented in businesses in developed countries. With the help of the developing information and communication technologies, it is seen that the integration and cooperation between businesses spreads in a value-creating way. In today's world, instead of the concept of being competitive one by one, a competitive environment is formed by the whole of the supply chains in which they are located. In this environment, businesses in our country need to act with the principle of business partnership, create an environment of trust and open their business processes to each other by taking the ways of cooperation with their suppliers and customers further, in order to remain competitive and transfer their business to future generations. Thus, with the coordination of a chain management that will be created with the disappearance of borders within the supply chain, instead of optimizing the objectives of the enterprises one by one, it will be possible to obtain more benefits for all chain members thanks to the optimization method in the whole chain.

In summary, competitive advantage can be brought to the entire supply chain with the information generated (depending on the amount of information sharing) using appropriate IT systems in agri-food SCM. IT is a valuable tool for responsive but limited agribusiness supply chain management. However, the rapid development of IT and the Internet promises to minimize these limits in the near future. 


\section{References}

Budiarto, D. S., Prabowo, M. A., \& Herawan, T. (2017). An integrated information system to support supply chain management and performance in SME's. Journal of Industrial Engineering and Management, 10(2), 373-387. https://doi.org/10.3926/jiem.2180

Chandrasekaran, N., \& Raghuram, G. (2014). Agribusiness Supply Chain Management. CRC Press Taylor \& Francis Group. https://doi.org/10.1201/b16704

Chopra, S., \& Meindl, P. (2001). Supply Chain Management. Prentice Hall

Christopher, M. C. (1992). Logistics. The strategic issue. Chapman and Hall.

Cooper, M. C., \& Ellram, L. M. (1993). Characteristics of SCM and the implications for purchasing and logistics strategy. The International Journal of Logistics Management, 4(2), 13-24. https://doi.org/10.1108/09574099310804957

Dubey, S. K., Singh, R., Singh, P. S., Mishra, A., \& Singh, N. V. (2020). A brief study of value chain and supply chain. Mahima Publications

Ellinger, A. E., Daugherty, P. J., \& Plair, Q. J. (1999). Customer satisfaction and loyalty in supply chain: the role of communication. Transportation Research Part E: Logistics and Transportation Review, 35(2), 121-134. https://doi.org/10.1016/S1366-5545(99)00006-X

Fisher, M. (1997). What is The Right Supply Chain for Your Product. Harward Business Review.

Gadzhiev, G. B. (2014). The current state of exports in the agribusiness system and directions of regulation of foreign economic activity. Science and business: ways of development, 8(38), 146148.

Hannus, T., Poignee, O., \& Schiefer, G. (2003). The implementation of a webbased supply chain information system-Experiences with a regional quality grain program. Presented at the EFITA 2003 Conference.

Harshit, S., Shreemi, S., Shrinath, P., Vartika, J., \& Vrajkumar, B. (2021). Sustainable Supply Chain Management. SAMVAD. International Journal of Management, 22, 36. https://doi.org/10.53739/samvad/2021/v22/164045

Hasanli, Y., Hajiyev, N., \& Kazimov, F. (2019). The Impact of Natural Resource Exploitation on Balanced Development with Modified Reproduction Scheme Based on Supply Chain Management. Int. J. Sup. Chain, 8(1), 438-443.

Hitt, M. A., Xu, K., \& Carnes, C. M. (2016). Resource-based theory in operations management research. Journal of Operations Management, 41(1), 77-94. https://doi.org/10.1016/j.jom.2015.11.002

Kim, B. (2000). Coordinating an innovation in supply chain management. European Journal of operational research, 123(3), 568-584. https://doi.org/10.1016/S0377-2217(99)00113-7

Lambert, D., \& Cooper, M. C. (2000). Issues in Supply Chain Management. Industrial Marketing Management, 29, 65-83. https://doi.org/10.1016/S0019-8501(99)00113-3

Leroux, N., Wortman, Jr. M. S., \& Mathias, E. D. (2001). Dominant factors impacting the development of business-to,-business (B2B) e-commerce in agriculture. Intl. Food and Agribusiness Management Review 4, 205-218. https://doi.org/10.1016/S1096-7508(01)00075-1

Lim, D., \& Palvia, P. C. (2001). EDI in Strategic Supply Chain: Impact On Customer Service. International Journal of Information Management, 21, 193- 211. https://doi.org/10.1016/S02684012(01)00010-X

Mabert, A. V., \& Venkataramanan, M. A. (1998). Special Research Focus on Supply Chain Linkages: Challenges for Design and Management in the 21st Century. Decisions Sciences, 29, 537-552. https://doi.org/10.1111/j.1540-5915.1998.tb01353.x

Matsubara, S. (2011). Consideration Concerning Supply Chain Management in Agribusiness. Journal of Rural Problems, 47, 120-125. https://doi.org/10.7310/arfe.47.120

Miethlich, B., Belotserkovich, D., Abasova, S., Zatsarinnaya, E., \& Veselitsky, O. (2020). Digital Supply Chain Management-New Competitiveness Imperative for Economic Development. Int. J. Sup. Chain, 9(5), 495-501.

Sachs, G. (2000). B2B: 2B or not 2B, the second survey. Accessed from http://www.gs.com/ hightech/research/b2b-second-survey.pdf 
Salin, V. (1998). Information technology in agri-food supply chains. International Food and Agribusiness Management Review, 1, 329-334. https://doi.org/10.1016/S1096-7508(99)80003-2

Viswanathan, S., \& Piplani, R. (2001). Coordinating Supply Chain Inventories Through Common Replenishment Epochs. European Journal of Operational Research, 129, 277-286. https://doi.org/10.1016/S0377-2217(00)00225-3

Vitorino Filho, V. A., \& Moori, R. G. (2020). RBV in a context of supply chain management. Gestão \& Produção, 27(4), e4731. https://doi.org/10.1590/0104-530X4731-20

Yao, A. C., \& Carlson, J. G. (1999). The Impact of Real Time Data Communication on Inventory Management. Int. J. Production Economics, 213-219. https://doi.org/10.1016/S09255273(98)00234-5 